\title{
Adult-Born Hippocampal Dentate Granule Cells Undergoing Maturation Modulate Learning and Memory in the Brain
}

\author{
Wei Deng, Michael D. Saxe, Iryna S. Gallina, and Fred H. Gage \\ Laboratory of Genetics, The Salk Institute for Biological Studies, La Jolla, California 92037
}

\begin{abstract}
Adult-born dentate granule cells (DGCs) contribute to learning and memory, yet it remains unknown when adult-born DGCs become involved in the cognitive processes. During neurogenesis, immature DGCs display distinctive physiological characteristics while undergoing morphological maturation before final integration into the neural circuits. The survival and activity of the adult-born DGCs can be influenced by the experience of the animal during a critical period when newborn DGCs are still immature. To assess the temporal importance of adult neurogenesis, we developed a transgenic mouse model that allowed us to transiently reduce the numbers of adultborn DGCs in a temporally regulatable manner. We found that mice with a reduced population of adult-born DGCs at the immature stage were deficient in forming robust, long-term spatial memory and displayed impaired performance in extinction tasks. These results suggest that immature DGCs that undergo maturation make important contributions to learning and memory.
\end{abstract}

\section{Introduction}

The hippocampal dentate gyrus (DG) is one of two brain regions with continuous addition of new neurons throughout life (Gage, 2000). Adult hippocampal neurogenesis is a complex process originated from the proliferation of neural progenitor cells (NPCs) located in the subgranular zone (SGZ). The majorities of NPC progenies are specified to become dentate granule cells (DGCs) and go through the initial differentiation and migrate into the inner granule cell layer within a week of their birth. Between 1 and 4 weeks after birth, newborn DGCs undergo a long process of morphological and physiological maturation and display characteristics distinct from mature DGCs before they fully integrate into the neural circuits and become indistinguishable from mature DGCs. During this time, newborn DGCs project their axons to CA3 and grow dendrites into the molecular layer, starting to form both afferent and efferent synapses (Hastings and Gould, 1999; Zhao et al., 2006; Toni et al., 2007, 2008; Faulkner et al., 2008). In this manuscript, we will refer to these newborn DGCs at 1-4 weeks of age, going through these important maturation processes, as "immature neurons" for convenience. Intriguingly, the immature DGCs, which start to receive GABAergic inputs within $8 \mathrm{~d}$ of birth and glutamate inputs by $18 \mathrm{~d}$, have a lower threshold for long-term potentiation (LTP) induction and enhanced synaptic plasticity (Schmidt-Hieber et al., 2004; Espósito et al., 2005; Ge et al., 2006). Furthermore, this immature stage corresponds to a "critical period," when the ex-

\footnotetext{
Received July 14, 2009; revised Sept. 9, 2009; accepted Sept. 10, 2009.

Funding was provided by a National Institutes of Health Translational Cardiovascular Science and Medicine Training Grant, the Lookout Fund, the McDonnell Foundation, the United States National Institutes of Health (NS-05050217 and NS-05052842), and the National Institute on Aging (AG-020938). We thank Dr. Rüdiger Klein for providing the Nestin promoter/enhancer plasmid, Drs. Sebastian Jessberger, Chunmei Zhao, and James B. Aimone for constructive comments on this manuscript, and Mary Lynn Gage for editorial comments.

Correspondence should be addressed to Fred H. Gage at the above address. E-mail: gage@salk.edu.

M. D. Saxe's present address: BrainCells Inc., 3565 General Atomics Court, Suite 200, San Diego, CA 92121.

DOI:10.1523/JNEUROSCI.3362-09.2009

Copyright $\odot 2009$ Society for Neuroscience ～0270-6474/09/2913532-11\$15.00/0
}

periences of the animals could modulate the survival and subsequent experience-specific responsiveness of adult-born DGCs (Tashiro et al., 2006, 2007). In addition, the activity of immature DGCs is critical for their survival and subsequent network incorporation (Tashiro et al., 2006, 2007; Kee et al., 2007). Because of these special properties and modes of regulation, we and others have postulated that immature DGCs play important roles in hippocampus-dependent function.

Several approaches have been developed to study the functions of adult neurogenesis, including low-dose brain irradiation, systemic treatment with anti-mitotic agents, and utilization of aging as naturally occurring neurogenic reduction, though they have provided inconsistent and sometimes conflicting results (Shors et al., 2001; Drapeau et al., 2003; Santarelli et al., 2003; Snyder et al., 2005). The undesired side effects of these approaches may lead to data discrepancies. Recently, several transgenic mouse lines have been generated for more specific manipulation of adult neurogenesis (Saxe et al., 2006; Dupret et al., 2008; Imayoshi et al., 2008; Zhang et al., 2008). Behavioral analyses of these transgenic mice also resulted in conflicting data with regard to the role of adult neurogenesis in either spatial learning and memory or contextual fear conditioning. Moreover, most of these studies examined the behavioral consequences of chronic neurogenesis ablation. It remains elusive whether the cognitive contributions of adult-born DGCs are dependent on their maturation stages.

To specifically investigate the importance of immature DGCs, we developed Nestin-tk transgenic mice, which allow us to reduce adult neurogenesis in a temporally regulatable manner. The transient nature of this model makes it possible to observe the reappearance of the wild-type phenotype after the affected population of adult-born DGCs was replenished. By subjecting these mice to several behavioral paradigms, we revealed that transgenic mice with reduced numbers of DGCs at the immature stage displayed deficits in long-term memory retention in the Morris water maze (MWM), and in the extinction of both spatial preference and the context-evoked fear. These results suggest that immature 
DGCs make important contributions to hippocampus-dependent cognitive functions.

\section{Materials and Methods}

Generation of Nestin-tk transgenic mice and drug treatments. We constructed a transgene containing $5 \mathrm{~kb}$ Nestin promoter, herpes simplex virus (HSV) thymidine kinase (tk) gene (HSV-tk gene), IRES-GFP, SV40 polyadenylation site, and $2 \mathrm{~kb}$ Nestin enhancer from the second intron in pBluescript plasmid. The transgene was released from the plasmid by NotI digestion and injected into the pronuclei of fertilized eggs $(\mathrm{CB} 6 \mathrm{~F} 1 \times \mathrm{CB} 6 \mathrm{~F} 1)$ using standard procedures (Hogan et al., 1994). Three founders were identified by PCR genotyping using $5^{\prime}$ primer TTCCGGGGTGTCTGGCTGTATCTC and 3' primer CGGCACGCTGTTGACGCTGTTA. They were bred into C57BL/6 background via backcrossings. The animals used for histology studies were from N2-N4 generations. The animals used for water maze tests had been backcrossed to C57BL/6 for at least five generations. Animals were housed two to five per cage under standard $12 \mathrm{~h}$ light/dark cycles with ad libitum access to food and water. Bromodeoxyuridine (BrdU) was injected intraperitoneally at either $100 \mathrm{mg} / \mathrm{kg}$ in the histological experiments or $50 \mathrm{mg} / \mathrm{kg}$ in the behavioral experiments. Ganciclovir (GCV) was injected intraperitoneally at $100 \mathrm{mg} / \mathrm{kg}$. GCV treatment for behavioral experiments started when the animals were $\sim 8$ weeks old. For all experiments, we used both male and female mice in age-matched litters. All experimental procedures were approved by the Institutional Animal Care and Use Committee at The Salk Institute for Biological Studies.

Histology and quantifications. Mice were perfused and brain sections were prepared according to previously reported procedures (Zhao et al., 2006). Brain sections from a one-in-six series were selected for immunostaining. The following primary antibodies were used: rat anti-BrdU (1:200, Accurate), mouse anti-BrdU (1:100, BD), goat anti-NeuroD (Liu et al., 2000) (1:100, Santa Cruz Biotechnology), goat anti-doublecortin (Couillard-Despres et al., 2005) (1:200, Santa Cruz Biotechnology), mouse anti-NeuN (1:100, Millipore Bioscience Research Reagents), rabbit anti-Ki67 (1:1000, Novocastra Laboratories), rat anti-CD68 (Meshi et al., 2006) (1:500, Serotec), mouse anti-Ox42 (also known as CD11b, 1:200), and rabbit anti-activated caspase 3 (1:300, Cell Signaling Technology). CD68 and Ox42 are two independent markers for activated microglia. All secondary antibodies were used in 1:250 dilutions and were from Jackson ImmunoResearch. The numbers of BrdU and Ki67 cells were quantified using fluorescent microscopy following previous procedures (van Praag et al., 1999). The numbers of Dcx cells were quantified stereologically using an optical fractionator in the Stereo Investigator software under fluorescence microscope. The experimenter was blind to the genotypes of the mice for all quantifications.

Water maze tests. Mice were trained in the standard hidden platform of the water maze at various time points after GCV treatment. The water maze was a circular tank $\sim 1.2 \mathrm{~m}$ in diameter filled with water, which was made opaque with nontoxic white paint. The water temperature was set at $25 \pm 1^{\circ} \mathrm{C}$. For the standard version of MWM, the platform was in a constant position and was hidden $1 \mathrm{~cm}$ below the surface of water. Mice were trained four trials per day for $8 \mathrm{~d}$. For training trials, the mouse was released, facing the wall of the tank, at a randomly chosen point from each quadrant for the four trials. The sequence of releasing quadrants within a day was randomly chosen and was the same for all mice. Each training trial lasted until the mouse located the platform, or for a maximum of $40 \mathrm{~s}$. The mouse was put onto the platform if it failed to find the platform. All mice were allowed to stay on the platform for $15 \mathrm{~s}$ afterward. During a probe trial, the platform was removed from the water maze and the mice were allowed to swim for $60 \mathrm{~s}$. For the extinction paradigm, mice were trained for four trials per day for $6 \mathrm{~d}$, followed by $2 \mathrm{~d}$ of extinction. On days of extinction training, mice were subjected to two probe trials that lasted for $40 \mathrm{~s}$ and were spaced at least $2 \mathrm{~h}$ apart. For detailed analysis of extinction, we used pb1-pb2 (i.e., duration in the target quadrant in probe test 1 -duration in the target quadrant in probe test 2 ) as the extinction index. All water maze performances were recorded and analyzed by Ethovision video tracking system and software. The experimenter was blind to the genotypes of animals for the water maze tasks.
Contextual fear extinction. The fear conditioning apparatus and software were obtained from Med Associates. Mice were trained in contextual fear conditioning 1 week after the $14 \mathrm{~d}$ GCV treatment. Contextual fear conditioning was conducted in context A. Context A consisted of a conditioning chamber in a sound-attenuated cubicle measuring $64 \times$ $42 \times 76 \mathrm{~cm}$. The conditioning chamber, measuring $29 \times 25 \times 26 \mathrm{~cm}$, had a Plexiglas roof and front door, aluminum side walls, and a plastic back wall. The grid floor of the chamber, in which foot shocks were delivered, consisted of 36 steel rods that were $\sim 3 \mathrm{~mm}$ in diameter, stainless, and spaced $5 \mathrm{~mm}$ apart. A fan installed on one of the side walls of the cubicle provided background noise. Chambers were not additionally scented and were cleaned with 70\% isopropanol after each test. Mice were acclimated to the procedure room for at least $30 \mathrm{~min}$ before testing. An individual mouse was put into the training chamber (context A) and allowed to freely explore for $3 \mathrm{~min}$ before the delivery of a $0.7 \mathrm{~mA}$ foot shock that lasted for $2 \mathrm{~s}$. The freezing behaviors observed during the 3 min preshock were scored as the precontextual fear conditioning (preCFC) baseline. Contextual fear conditioning was tested $24 \mathrm{~h}$ later by introducing mice to context A for 3 min followed by a reminder foot shock $(0.7 \mathrm{~mA})$ that lasted for only $0.5 \mathrm{~s}$. The freezing behaviors during the $3 \mathrm{~min}$ before shock were scored as the index for the conditioned contextual fear. Mice were subsequently subjected to extinction training either $24 \mathrm{~h}$ later or 4 weeks later (see Fig. 6). In each extinction trial, mice were put into the training chamber (context $\mathrm{A}$ ) for $10 \mathrm{~min}$ without foot shocks. Each mouse was trained for $3 \mathrm{~d}$ with two daily extinction trials, which were spaced at least $2 \mathrm{~h}$ apart. The freezing behaviors in the first 3 min of extinction trials were scored. Twenty-four hours after the extinction training, mice were returned to context A for a 5 min test. At least $2 \mathrm{~h}$ after the context $\mathrm{A}$ test, mice were introduced to context $\mathrm{B}$ and allowed to explore for 5 min without foot shocks. Context B was considerably different from context A in several ways: (1) the shape of the chamber was changed by putting a curved plastic board with printed patterns inside the chamber to conceal the side walls and the back wall, (2) a plastic board with printed patterns was inserted underneath the grid floor to provide a different patterned floor, though a crescent-shaped grid floor was still exposed, (3) five posters were hung inside the sound-attenuated cubicle to provide distinct visual cues outside the chamber, (4) the chamber was scented with vanilla extract, (5) the fan on the side wall of the cubicle was turned off and $70 \mathrm{~dB}$ white noise was delivered through a speaker attached to the side wall of the chamber, and (6) the chamber was cleaned with Windex after each test. For consistency, the first $3 \mathrm{~min}$ of the tests were scored. The test in context A could be regarded as an extension of extinction training and was included in the extinction curve below (see Fig. 7). The behaviors of the mice were recorded and analyzed using the video freeze software (Med Associates).

Statistics. One-way ANOVA and unpaired two-tailed $t$ tests were used to analyze histological data. One-way ANOVA with Fisher's PLSD for post hoc test was used for probe test analysis. Two-way ANOVA with repeated measure and two-tailed $t$ tests were used to analyze behavioral data in MWM and contextual fear extinction paradigms. $p<0.05$ was considered as significant and all data were presented as mean \pm SEM.

\section{Results \\ Drug-dependent reduction of hippocampal neurogenesis in Nestin-tk mice}

To investigate the function of the adult-born DGCs at specific stages of maturation, a system need to be developed that would allow the manipulation of adult-born DGCs in both inducible and transient manners. For this purpose, we generated Nestin-tk transgenic mice in which the HSV-tk gene is expressed from the Nestin promoter/enhancer, a well characterized promoter for neural progenitors in the adult brain (Yamaguchi et al., 2000; Mignone et al., 2004). By RT-PCR analysis, we detected expression of the Nestin-tk transgene only in the brain among several tissues surveyed (supplemental Fig. 1A, available at www. jneurosci.org as supplemental material). In Nestin-tk mice, the administration of GCV, a nucleotide analog, ablates only the dividing tk-expressing cells, adding another layer of specificity to 

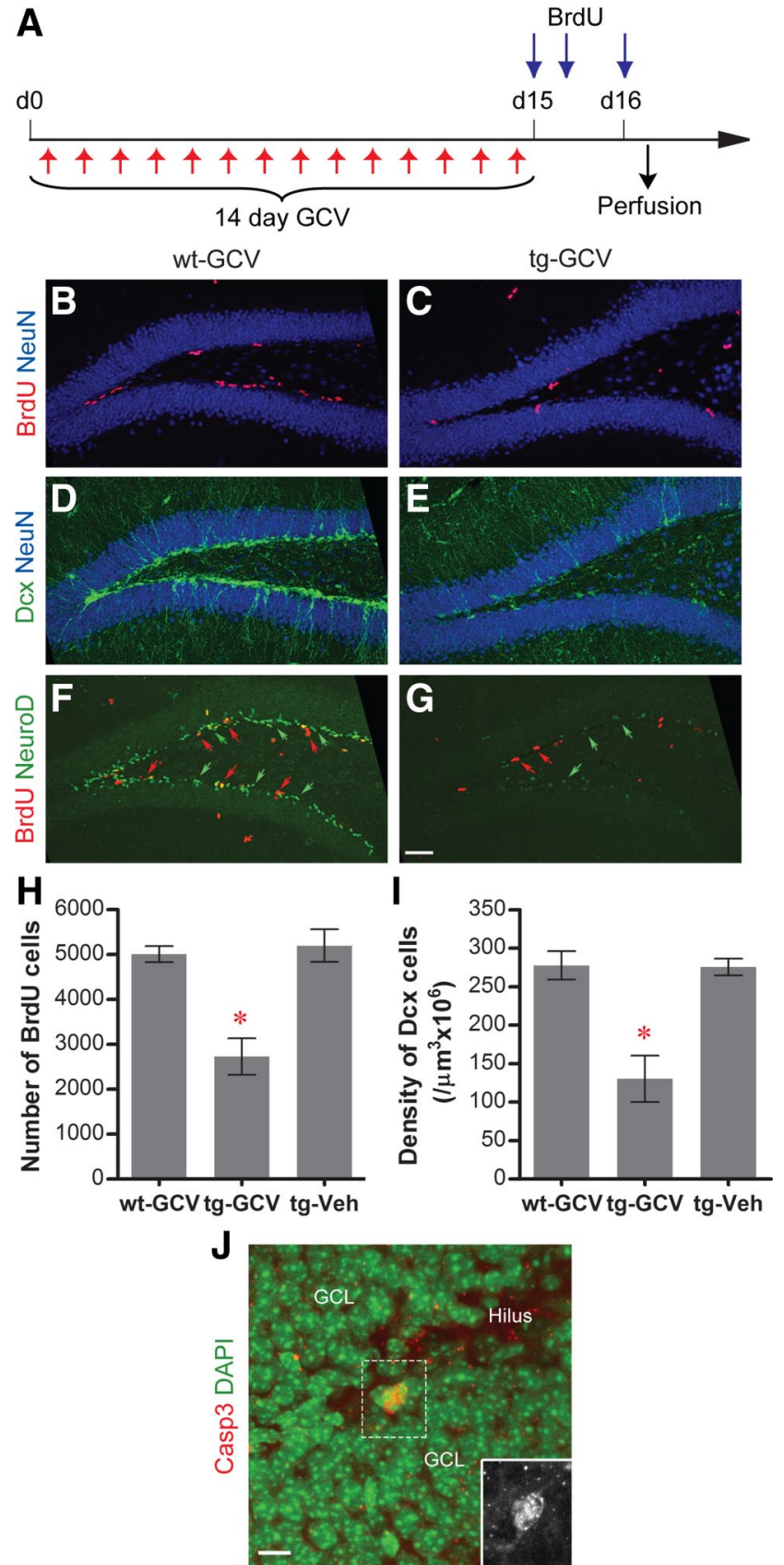

Figure 1. Reduction of neurogenesis in the DG of GCV-treated Nestin-tk transgenic mice. $\boldsymbol{A}$, The experimental scheme. $\boldsymbol{B}-\boldsymbol{G}$, Representative confocal images of adult DG from wt-GCV and $\operatorname{tg}$-GCV mice labeled by cell proliferation marker $\operatorname{BrdU}$ (red in $\boldsymbol{B}, \boldsymbol{C}, \boldsymbol{F}, \boldsymbol{G}$, red arrows in $\boldsymbol{F}, \boldsymbol{G}$ ), immature neuron markers $D c x$ (green in $\boldsymbol{D}, \boldsymbol{E}$ ) and NeuroD (green staining and green arrows in $\boldsymbol{F}, \boldsymbol{G}$ ), and mature neuron marker NeuN (blue, $\boldsymbol{B}-\boldsymbol{E}$ ) in DG. $\boldsymbol{H}$, BrdU cell number is reduced in $\mathrm{tg}$-GCV compared to wt-GCV and tg-Veh (ANOVA, $F_{(2,21)}=17.20, p<4 \times 10^{-5}, n=8$ for each group). I, Density of Dcx cells is reduced in tg-GCV (ANOVA, $F_{(2,21)}=15.70, p<7 \times$ $10^{-5}, n=8$ for each group). $\boldsymbol{J}, \boldsymbol{K}$, Increased apoptosis in $\mathrm{tg}-\mathrm{GCV}$ mice. $\boldsymbol{J}$, Representative image of the activated-caspase 3-positive cells; the inset is a blowup for the activated-caspase 3-positive cell without the DAPI counterstaining. $\boldsymbol{K}$, The number of activated-caspase 3-positive cells is increased in $\mathrm{tg}-\mathrm{GCV}$ mice $\left(t_{(6)}=4.02, p<0.0070 ; n=4\right.$ for each group). Scale bars: $\boldsymbol{G}$ (for $\boldsymbol{B}-\boldsymbol{G}), 50 \mu \mathrm{m} ; \boldsymbol{J}, 10 \mu \mathrm{m} .{ }^{*} p<0.01$. Error bars represent \pm SEM.

the system. To test this system, we treated transgenic mice daily with GCV for $14 \mathrm{~d}$, followed by BrdU administrations to detect changes in neural progenitor cell proliferation (Fig. 1A). GCV treatment of transgenic mice (tg-GCV) greatly reduced the number of proliferating cells in SGZ, as indicated by the BrdU labeling, to $\sim 50 \%$ compared to those in GCV-treated wild-type littermates (wt-GCV) or vehicle-treated transgenic mice (tgVeh) (Fig. $1 B, C, H$ ). GCV treatment did not affect hippocampal neural progenitor proliferation in wild-type mice (supplemental Fig. $1 B-D$, available at www.jneurosci.org as supplemental material). Moreover, because of this subchronic treatment, the number of newly born DGCs was decreased in tg-GCV transgenic mice, as indicated by the significantly lower numbers of Dcxpositive or NeuroD-positive immature DGCs in tg-GCV mice (Fig. $1 D-G, I)$. As expected, GCV treatment also led to induced apoptosis in the transgenic mice, as indicated by the increased number of activated-caspase 3 -positive cells in tg-GCV mice (Fig. $1 \mathrm{~J})(48 \pm$ 5 for wt-GCV, $102 \pm 12$ for tg-GCV; $t_{(6)}=4.02, p<0.0070 ; n=$ 4 for each group). In addition, treating transgenic mice with GCV for only $4 \mathrm{~d}$ was sufficient to affect SGZ cell proliferation, as indicated by both BrdU and Ki67, another marker for proliferating cells (supplemental Fig. 2A-E,H,I, available at www. jneurosci.org as supplemental material). The GCV treatment also resulted in the reduction of cell proliferation in subventricular zone (SVZ), the other major region of neurogenesis in the adult brain (supplemental Fig. $2 F, G$, , available at www.jneurosci.org as supplemental material). We further examined whether neurogenesis was specifically affected by the GCV treatment in Nestin-tk mice. We treated another group of mice with GCV for $14 \mathrm{~d}$ and administered BrdU during the last $4 \mathrm{~d}$ of the GCV treatment (supplemental Fig. 3A, available at www.jneurosci.org as supplemental material). Nine weeks later, we perfused the mice and examined the effects of GCV treatment on neurogenesis and gliogenesis by immunohistochemical stainings. We found that the number of newly born DGCs, as indicated by NeuN and BrdU double labeling, was significantly lower in the tg-GCV mice, whereas the number of newly born glia in the tg-GCV mice, as labeled by both GFAP and BrdU, was comparable to that in wildtype littermates (supplemental Fig. 3B-E, available at www. jneurosci.org as supplemental material). Therefore, neurogenesis but not gliogenesis was reduced by the GCV treatment in Nestin-tk mice. Furthermore, the GCV-induced reduction in hippocampal neurogenesis was observed in two additional, independent lines of Nestin-tk transgenic mice, suggesting that the reduction was not due to integration of the transgene to a particular locus in the genome (supplemental Fig. 4, available at www. jneurosci.org as supplemental material). Finally, unlike some other approaches that also effectively reduced neurogenesis, GCV treatment caused neither loss in body weights of mice nor inflammation in the DG, similar to the observations of Dupret et al. (2008) in another transgenic mouse model (supplemental Fig. 5, available at www.jneurosci.org as supplemental material). These data indicate that we could specifically reduce neurogenesis using Nestin-tk transgenic mice with few side effects.

Although GCV treatment in the Nestin-tk animals greatly reduced the neural progenitor proliferation, it did not completely eliminate neural progenitors. We examined whether cell proliferation and neurogenesis could recover after drug withdrawal by labeling the proliferating cells with BrdU 4 weeks after the end of a $14 \mathrm{~d}$ GCV treatment (Fig. 2A). Both the number of BrdU cells $\left(3262 \pm 531\right.$ for wt-GCV, $3242 \pm 465$ for tg-GCV; $t_{(6)}=0.0298$, $p>0.97 ; n=4$ for each group) and the number of Dcx-positive cells $\left(290 \pm 37\right.$ for wt-GCV, $264 \pm 37$ for tg-GCV; $t_{(6)}=0.511$, $p>0.62 ; n=4$ for each group) in Nestin-tk mice were comparable to those in wild-type littermates, suggesting the recovery of both progenitor and immature DGC populations after 4 weeks (Fig. $2 B, C$ ). Because the GCV treatment specifically affects the proliferating cells, we sought to determine how quickly the cell proliferation in the DG could recover. We perfused mice 1, 3, or 
A
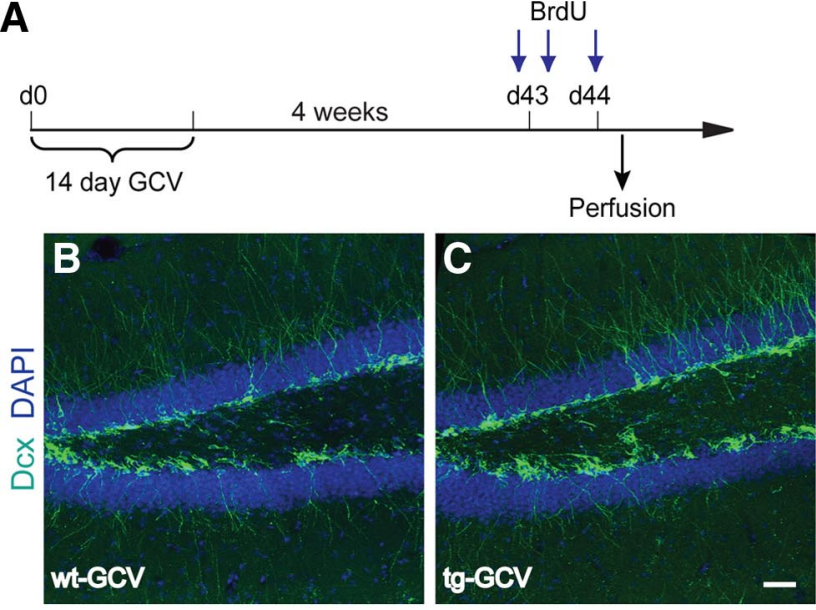

D

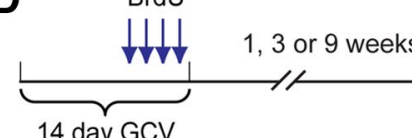

E

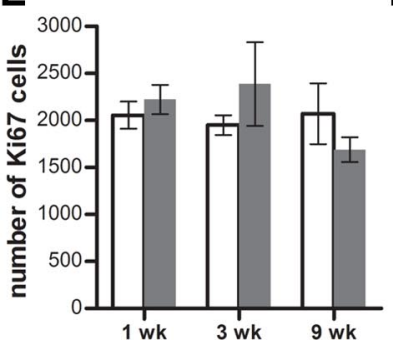

$\mathbf{F}$

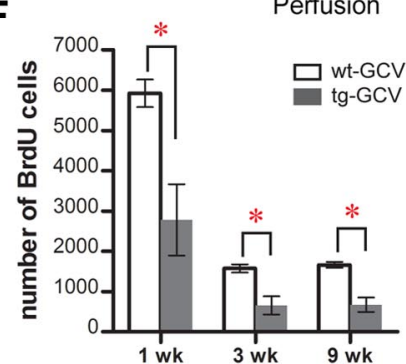

Figure 2. Recovery of progenitor cell proliferation and neurogenesis in the DG after drug withdrawal in Nestin-tk transgenic mice. $\boldsymbol{A}$, The experimental scheme for $\boldsymbol{B}$ and $\boldsymbol{C} . \boldsymbol{B}, \boldsymbol{C}$, Representative confocal images of adult DG from wt-GCV and tg-GCV mice labeled by immature neuron marker $D c x$ (green). Nuclear marker DAPl is in blue. See text for quantifications. D, The experimental scheme for $\boldsymbol{E}$ and $\boldsymbol{F}$. $\boldsymbol{E}$, Ki67 cell numbers are similar between tg-GCV and wt-GCV at 1, 3, and 9 weeks after GCV treatment. $\boldsymbol{F}$, BrdU cell numbers are reduced in tg-GCV at 1,3 , and 9 weeks after $\mathrm{GCV}$ treatment. See supplemental Table 1, available at www.jneurosci.org as supplemental material, for statistics for $\boldsymbol{E}$ and $\boldsymbol{F}$. Scale bar: (in $\boldsymbol{C} \boldsymbol{B}$ and $\boldsymbol{C}, 50 \mu \mathrm{m} .{ }^{*} p<0.01$. Error bars represent \pm SEM.

9 weeks after the $14 \mathrm{~d}$ GCV treatment and quantified cell proliferation at the time of the perfusion using Ki67 as the marker (Fig. $2 D)$. BrdU was administrated to mice during the last $4 \mathrm{~d}$ of GCV treatment to assess the GCV-induced reduction in cell proliferation. Although quantification of BrdU cells indicated a reduction of cell proliferation during GCV treatment (Fig. $2 F$ ), we found that Ki67 cell numbers in Nestin-tk animals were comparable to those in wild-type littermates at all three time points (Fig. 2E), suggesting that cell proliferation recovered as early as 1 week after GCV withdrawal. This capacity for recovery of cell proliferation and neurogenesis after drug withdrawal provides us a system in which the number of adult-born DGCs can be reduced at a specific maturation stage through manipulating the time interval between the GCV treatment and behavioral tasks. Moreover, we can employ this system to test whether the phenotype of the GCV-treated transgenic mice can be rescued after the replenishment of the affected adult-born DGC population, thus confirming the importance of neurogenesis for the tested function.

\section{Impairment of spatial memory formation in mice with reduced immature DGC population}

To examine whether and how a reduction of immature DCCs would affect learning and memory, we trained mice in the stan- dard hidden platform version of MWM, which examined reference memories of mice after repeated training. We then subjected mice to an $8 \mathrm{~d}$ MWM training paradigm 1 week after a $14 \mathrm{~d}$ GCV treatment (Fig. 3A). Starting from day 4 of training, a probe trial was conducted 3 to $4 \mathrm{~h}$ after the last training trial to assess shortterm recall. Probe tests were also performed at 1, 2, and 3 weeks after training to evaluate long-term memory retention. We found that the transgenic mice were not significantly different from wild-type littermates in acquisition of the task, as indicated by both latency to the platform and swimming distance (Fig. 3B). Both transgenic and wild-type mice expressed short-term retention of the platform location by spending significantly more time in the target quadrant on days 4 and 5, respectively (Fig. 3C). This finding indicates that transgenic mice do not have spatial learning or short-term recall defects at the initial stage of learning, when the performance improves rapidly.

The performance of transgenic mice on the probe trials in the second asymptotic phase of learning showed an interesting pattern. We found that transgenic mice spent progressively less time in the target quadrant during probe tests over training (Fig. 3C). Eventually, on day 8 of training, transgenic mice spent chance percentage of time in the target quadrant during the probe test, whereas wild-type controls performed progressively better over days of training in the probe trials. Furthermore, this changed performance in the probe trials seemed to be long lasting. Transgenic mice showed no preference for the target quadrant 1 week after training, in contrast to wild-type controls (Fig. 3D). Neither group recalled the location of the platform 2 or 3 weeks after training (data not shown).

In the above experiment, the affected population of young DGCs would have been 1-3 weeks old at the beginning of the water maze training, 2-4 weeks old at the end of the training, and 3-5 weeks old at the time of the long-term retention test. Therefore, the phenotypes we observed were likely due to the selective loss of adult-born DGCs before they were fully matured. To examine whether reduction in the numbers of adult-born DGCs at more mature stages resulted in a similar phenotype, we tested two additional cohorts of mice either 3.5 weeks or 9 weeks after GCV treatment (Fig. 4A). In the cohort trained 3.5 weeks after GCV treatment, young DGCs that were 3.5-5.5 weeks old at the start of training were affected. This group of DGCs exhibited more mature features than the 1- to 3-week-old DGCs, while still maintaining certain properties that were different from mature DGCs (Espósito et al., 2005; Ge et al., 2007). In the cohort trained 9 weeks after GCV treatment, the affected DGCs, 9-11 weeks old, were fully matured (Espósito et al., 2005; Ge et al., 2007). In both cohorts of mice, the tg-GCV performed similarly to the wt-GCV mice in acquisition, as indicated by both the distance moved and the latency to the platform (Fig. $4 B, C$ ) (data not shown). Moreover, we did not detect any deficits of memory retention in the transgenic mice in the short-term or long-term probe trials in either cohort of mice (Fig. 4D-G). Quantification of BrdU cells revealed that hippocampal neurogenesis in these two cohorts was reduced to a degree similar to that seen in the 1-week-delay cohort (supplemental Fig. 6, available at www.jneurosci.org as supplemental material), suggesting that the lack of impairment in probe trials was not due to the extent of the reduction of neurogenesis. Together, these data suggest that the reduction in the immature DGC population is responsible for the deteriorating performance of the transgenic mice in probe trials under our experimental conditions. 
Long-term memory deficit in mice with reduced immature DGC population

The tg-GCV mice in the above experiment (Fig. 3) did not display any deficits in the probe trial on day 4 but exhibited deteriorating performance in the subsequent daily probe trials (Fig. 3). We suspect this phenotype is caused by the repeated probe trials and the weakness of the memory formation in tg-GCV mice. If this were the case, we hypothesized that transgenic mice would not perform as well as wild-type mice in the long-term retention test but might perform adequately on the first short-term probe test if the intervening probe trials were removed. Thus, we trained a new cohort of mice in the standard hidden platform version of MWM for $8 \mathrm{~d}, 1$ week after GCV treatment, without the intervening daily probe trials. Probe tests were performed on days 8 and 15 to assess the animals' short-term retention and long-term retention, respectively (Fig. 5A). Consistent with the results of previous experiments, the acquisition of the task was found to not be affected in the transgenic mice (Fig. $5 B)$. To evaluate the memory retentions of mice in probe tests, we measured four parameters: time that mice spent in the target quadrant (duration), frequency that mice entered the target quadrant (frequency), latency that mice reached the virtual platform area (latency) and frequency that mice crossed the virtual plat-

form area (platform crossings). Of these measures, platform crossings and the latency to the virtual platform are considered more stringent measures of spatial memory (Maei et al., 2009). For short-term retention, transgenic mice did not perform significantly differently from wild-type controls, as judged by all four parameters in the probe test on day 8 (Fig. $5 \mathrm{C}$ ). Thus, shortterm recall is not affected by the reduction in the immature DGC population in the absence of the intervening probe trials. However, for long-term retention, the duration, frequency and platform crossings were significantly lower in transgenic mice than in control littermates (Fig. 5C). The latency for the transgenic mice to reach the virtual platform was also much longer than that of wild-type mice, even though this difference was not statistically significant $(p<0.07)$ (Fig. 5C). Therefore, the long-term recall is affected by the reduction in the number of immature DGCs under our experimental conditions.

Our previous experiment suggested that probe trials could possibly influence the subsequent behavior of mice. To rule out the possibility that the probe trial used to assess the short-term retention on day 8 could interfere with the behavior of mice in the long-term retention test, we trained another cohort of mice and conducted probe tests only on day 15 to assess the animals' longterm retention without any intervening probe trials between the acquisition and the long-term retention test (Fig. $5 D$ ). Similar to the experiments described in Figure $5 A-C$, we did not observe any deficits in the transgenic mice in the task acquisition (Fig. $5 E$ ). Importantly, we did find that transgenic mice were defective in long-term memory retention, as judged by all four parameters in the probe test (Fig. 5F). This deficit in long-term retention in tg-GCV mice is consistent with previous reports that reduced neurogenesis could result in defective long-term memory (Snyder et al., 2005; Imayoshi et al., 2008; Jessberger et al., 2009). Importantly and differently from the previous studies, these data point to the reduction in the immature DGC population as being responsible for the deficit in long-term memory retention. Together with results from the previous experiments, our observations suggest that immature DGCs make significant contributions to learning and memory.

\section{No enhanced spatial memory extinction with reduced immature DGC population}

The deteriorating performance of $\mathrm{tg}-\mathrm{GCV}$ mice in repeated retention tests (Fig. 3) can also be explained alternatively. Because the probe trials used for retention test can be regarded as an extinction trial due to the lack of reinforcement in the absence of the hidden platform (Lattal and Abel, 2001), the progressively less time the tg-GCV mice spent in the target quadrant (Fig. 3) could be due to enhanced extinction. To directly examine the effects on spatial preference extinction of the immature DGC population reduction, we trained the GCV-treated mice in standard hidden platform water maze for $6 \mathrm{~d}$ and subjected them to consecutive probe trials (Fig. 6A) (see Materials and Methods). Consistent with previous findings, we found no acquisition deficits in the tg-GCV mice compared to wt-GCV mice (Fig. 6B, C). The global analysis of the probe trials did not reveal any performance difference between the tg-GCV and wt-GCV mice in extinction trials 


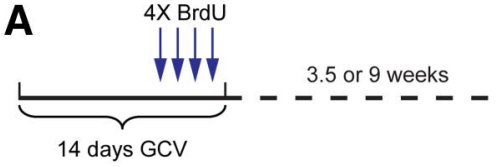

B

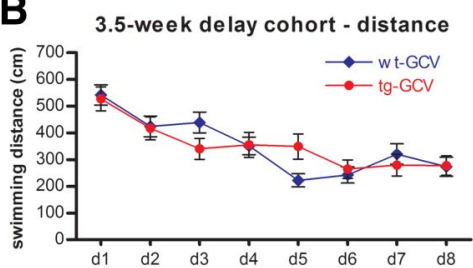

D

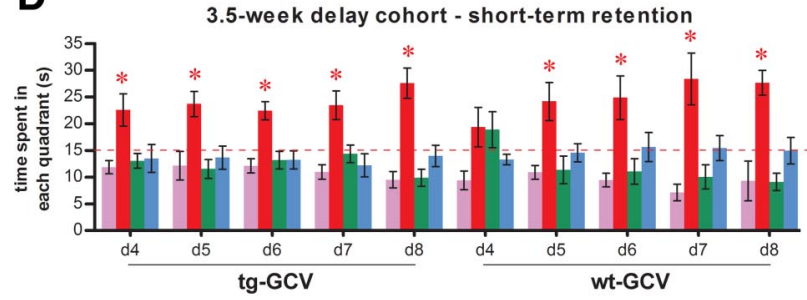

$\mathbf{F}$

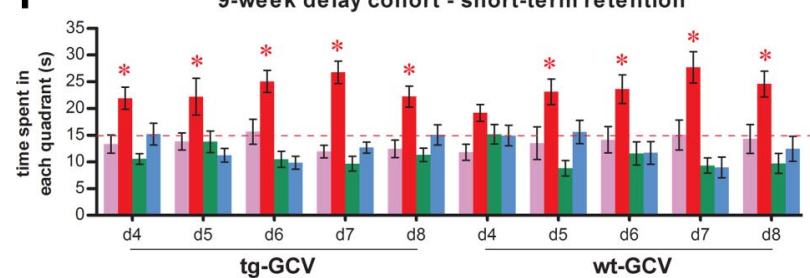

G - long-term retention

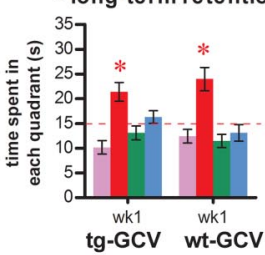

Figure 4. Learning and memory were not impaired in Nestin-tk mice if training started 3.5 or 9 weeks after GCV treatment. $\boldsymbol{A}$, The experimental scheme. $\boldsymbol{B}, \boldsymbol{C}$, Acquisition of the water maze task. GCV-treated transgenic mice in both the 3.5-week-delay cohort $\left(\boldsymbol{B}, \mathrm{ANOVA}, \boldsymbol{F}_{(1,17)}=1.946, p>0.98\right.$, for wt-GCV, $n=9$, for tg-GCV, $\left.n=10\right)$ and the 9-week-delay cohort (C, ANOVA, $F_{(1,22)}=0.036, p>0.85$, for wt-GCV, $n=13$, for $\left.\operatorname{tg}-\mathrm{GCV}, n=11\right)$ performed similarly to wild-type littermate controls, as indicated by distance moved in the maze. $\boldsymbol{D}$, Short-term retention from daily probe tests from day 4 to day 8 was similar in GCV-treated transgenic mice and wild-type littermates in the 3.5-week-delay cohort. $\boldsymbol{E}$, Long-term retention in the probe test 1 week after training was similar in GCV-treated transgenic mice and wild-type littermates in the 3.5-week-delay cohort. $\boldsymbol{F}$, Shortterm retention from daily probe tests from day 4 to day 8 was similar in GCV-treated transgenic mice and wild-type littermates in the 9-week-delay cohort. G, Long-term retention in the probe test 1 week after training was similar in GCV-treated transgenic mice and wild-type littermates in the 9 -week-delay cohort. The red dotted line indicates chance level $(15 \mathrm{~s})$. The hidden platform (black square) is located in the northwest quadrant. *Statistically significant difference between the target quadrant and all other quadrants. For detailed statistical analysis for $\boldsymbol{D}-\mathbf{G}$, see supplemental Table 2, available at www.jneurosci.org as supplemental material. Error bars represent \pm SEM.

(Fig. 6D). However, if we compare the performance in the first two extinction trials ( $\mathrm{pb} 1$ and $\mathrm{pb} 2$ ) in these mice and use the difference in the time spent in the target quadrant as the extinction index (pb1-pb2), we detected a small but significant reduced extinction in the tg-GCV mice (4.29 \pm 1.02 for wt-GCV, $-0.03 \pm 1.47$ for tg-GCV; $t_{(20)}=2.32, p<0.031 ; n=10$ for wt-GCV, $n=12$ for tg-GCV). Hence, instead of enhanced extinction of spatial preference, $t g-G C V$ mice with reduced numbers of immature DGCs were not as efficient as the wt-GCV mice in the extinction. Numerous studies have demonstrated that extinction is an active learning process instead of the forgetting or erasure of previously formed memories (reviewed by Ji and Maren, 2007). Therefore, the slightly affected extinction in tg-GCV mice suggests that immature DGCs may contribute to inhibitory learning during extinction.

\section{Impaired contextual fear extinction with reduced immature DGC population}

Given the suggestion of an extinction deficit in the MWM, we investigated extinction in another task. The extinction of fear

memory is the most commonly used paradigm to study extinction. Therefore, we used a contextual fear extinction paradigm in which the hippocampus has been shown to play a critical role (Fischer et al., 2007) to investigate the contribution of immature DGCs to inhibitory learning in extinction.

We trained mice for contextual fear conditioning 1 week after a $14 \mathrm{~d}$ GCV treatment in context A (Fig. 7A) (see Materials and Methods). Under our experimental conditions, the transgenic mice and wild-type controls displayed similar levels of freezing to context A when they were tested $24 \mathrm{~h}$ after training, suggesting no impaired contextual fear conditioning in the transgenic mice (Fig. $7 B$ ). Moreover, there was no significant difference between tg-GCV mice and wt-GCV mice in long-term retention of contextual fear memory (Fig. 7G) [comparing tg-GCV and wt-GCV in extinction trial $1, t_{(18)}=$ $1.38, p>0.183 ; n=10$ for each group]. Together with our previous results (Figs. $3,4)$, these data suggest that the effects of reduction in immature DGC population on the long-term retention can only be detected under certain experimental conditions (see Discussions).

To examine whether extinction of fear memory can be affected by a reduction in the immature DGC population, we subsequently trained mice to extinguish their freezing to context A by exposing them to context A repeatedly without the reinforcing foot shocks. During the extinction training, the transgenic mice were not able to reduce their freezing response to context A as efficiently as wild-type controls (Fig. 7C). In the postextinction tests, both groups of mice displayed similar freezing behavior in context $\mathrm{B}$, which was considerably different from context A (Fig. 7D), suggesting that the differential extinction behaviors between transgenic and wildtype mice were specific to the training context (i.e., context A). Together with our previous finding in MWM (Fig. 6D), these results suggest that the reduction in the immature DGC population led to impaired inhibition learning in extinction. This finding further suggests that the impaired performance of transgenic mice in repeated retention tests described in Figure 3 is likely due to inferior learning and memory instead of enhanced extinction.

To validate that it is the reduction in the immature DGC population that is responsible for the impaired extinction, we examined the extinction behavior in a new cohort of mice $\sim 4$ weeks after contextual conditioning to allow the recovery of the immature DGC population (Fig. 7E). In this cohort, the transgenic mice performed similarly to wild-type controls in both the conditioning and the extinction trials (Fig. $7 F-H$ ), suggesting that the deficit in extinction behavior is caused by the reduction in the immature DGC population specifically. However, in this cohort of mice, the age of fear memory before the extinction procedure, in addition to the maturation stage of the adult-born 
DGCs, was different from the previous experiment (Fig. $7 A-D$ ). To test whether immature DGCs are involved in the extinction of newly acquired contextual fear memory, we trained another cohort of mice 5 weeks after the GCV treatment and examined their extinction behavior right after the training (Fig. 7I). We again did not detect any difference in performance between tg-GCV and wt-GCV mice in either conditioning or extinction trials (Fig. $7 J-L)$. Together, these data indicate that immature DGCs are specifically involved in hippocampus-dependent inhibitory learning during extinction.

\section{Discussion}

During adult hippocampal neurogenesis, immature DGCs have unique characteristics within a few weeks after birth, including their morphogenesis and synaptogenesis (Espósito et al., 2005; Ge et al., 2006; Zhao et al., 2006; Toni et al., 2007, 2008; Faulkner et al., 2008), their unique electrophysiological properties (SchmidtHieber et al., 2004; Espósito et al., 2005; Ge et al., 2006, 2007) and their preferential incorporation into memory networks (Kee et al., 2007; Tashiro et al., 2007). However, evidence for the functional importance of DGCs undergoing maturation in animal behavior is lacking. Here, we generated Nestin-tk transgenic mice, which allowed us to reduce the number of adult-born DGCs at particular maturation stages by manipulating the time interval between drug treatment and experimental tests. Furthermore, we used the transient nature of the system to test the restoration of phenotype after the replenishment of the affected adult-born DGC population, confirm the requirement of neurogenesis for specific functional measures. Through behavioral analyses, we revealed that the reduction in the number of immature DGCs led to the defective long-term retention of spatial memory in MWM and impaired extinction of spatial preference and conditioned contextual fear, suggesting an important role for immature neurons in hippocampus-dependent learning and memory.

Similar Nestin-tk transgenic mouse models to reduce neurogenesis have also been described in two recent reports (Yu et al., 2008; Singer et al., 2009). Consistent with our study, drug-dependent reductions in neural progenitor proliferation and neurogenesis were reported in both studies. However, both studies reported a larger extent of neurogenesis reduction (>90\%) compared to our data ( $50 \%)$, possibly due to their prolonged, continuous
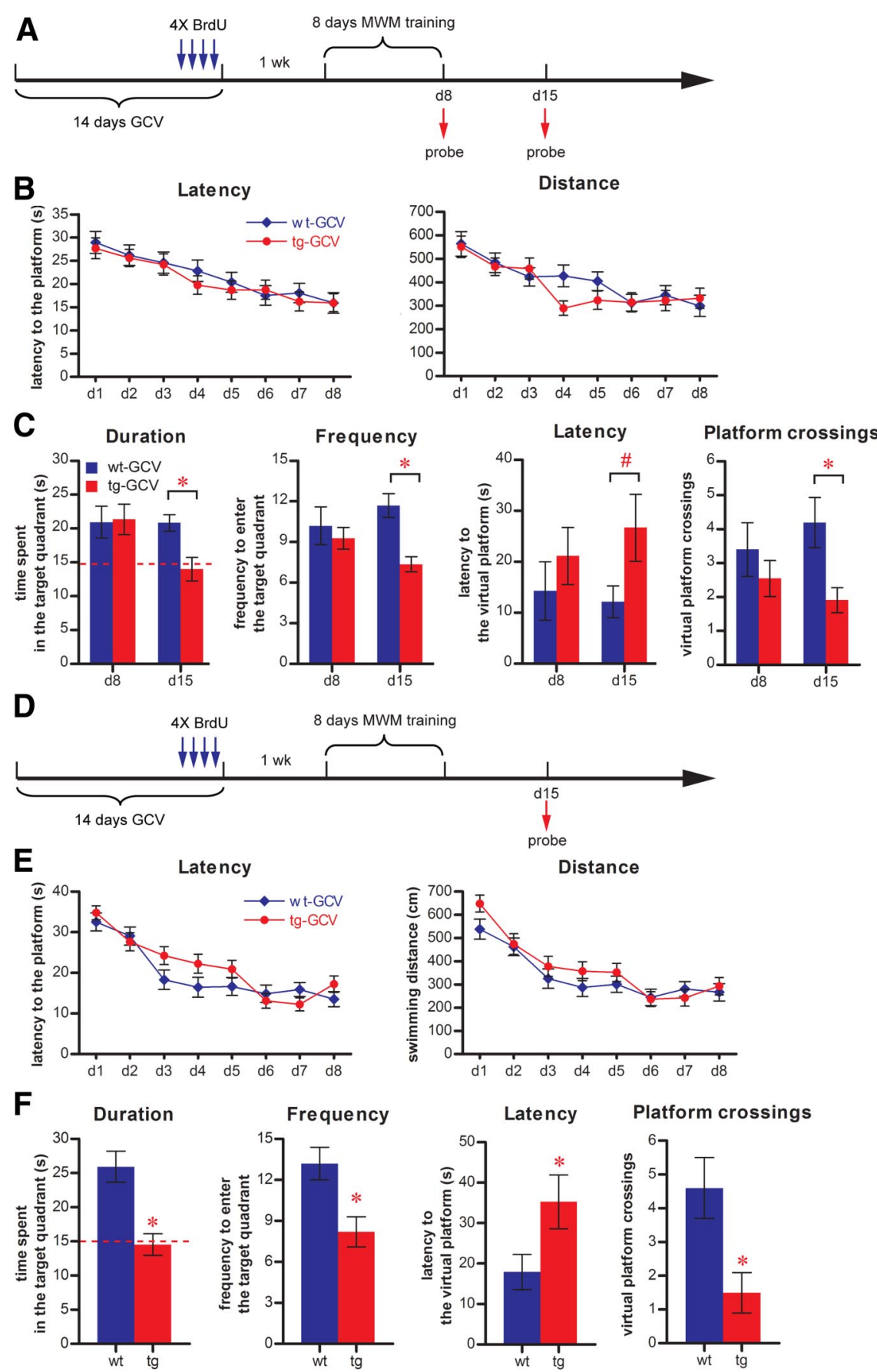

Figure 5. Impaired long-term retention in GCV-treated Nestin-tk transgenic mice. $\boldsymbol{A}$, The experimental scheme for $\boldsymbol{B}$ and $\boldsymbol{C}$. $\boldsymbol{B}$, Neither latency nor distance swum to reach the hidden platform during training was significantly different between tg-GCV and wt-GCV (latency: ANOVA, $F_{(1,19)}=0.184, p>0.67$; distance: ANOVA, $F_{(1,19)}=0.525, p>0.47$; for tg-GCV, $n=11$, for wt-GCV, $n=10)$. C, GCV-treated transgenic mice were defective in long-term retention on day 15 but not in short-term retention on day 8 , as indicated by duration in the target quadrant (duration), frequency of entering the target quadrant (frequency), latency to reach the virtual platform (latency), and frequency of entering the virtual platform (platform crossings) (duration: on day $8, F_{(1,19)}=$ $0.018, p>0.89$, on day $15, F_{(1,19)}=10.015, p<0.0051$; frequency: on day $8, F_{(1,19)}=0.345, p>0.56$, on day $15, F_{(1,19)}=$ $18.232, p<0.0004$; latency: on day $8, F_{(1,19)}=0.728, p>0.40$, on day $15, F_{(1,19)}=0.404, p>0.067$; platform crossings: on day $8, F_{(1,19)}=0.834, p>0.37$, on day $\left.15, F_{(1,19)}=8.097, p<0.0103\right)$. $\boldsymbol{D}$, The experimental scheme for $\boldsymbol{E}$ and $\boldsymbol{F}$. $\boldsymbol{E}$, Neither latency nor distance swum to reach the hidden platform during training was significantly different between tg-GCV and wt-GCV (latency: ANOVA, $F_{(1,19)}=0.604, p>0.44$; distance: ANOVA, $F_{(1,19)}=1.077, p>0.31$; for tg-GCV, $n=11$, for wt-GCV, $\left.n=10\right)$. $\boldsymbol{F}$, GCV-treated transgenic mice were defective in long-term retention as indicated by duration $\left(t_{(19)}=4.170, p<0.0005\right)$, frequency $\left(t_{(19)}=3.184, p<0.0049\right)$, latency $\left(t_{(19)}=2.142, p<0.0454\right)$, and platform crossings $\left(t_{(19)}=2.917, p<0.0088\right)$. The red dotted line indicates chance level (15s). *Statistically significant difference; " nonsignificant increase of latency in tg-GCV. Error bars represent \pm SEM. 
A
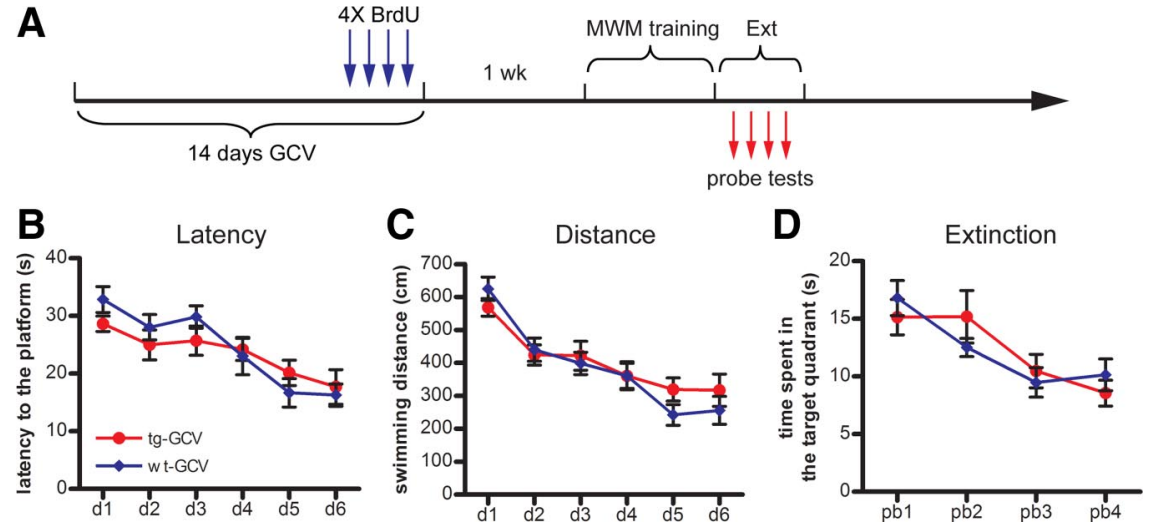

Figure 6. No enhancement of extinction of spatial memory in GCV-treated Nestin-tk transgenic mice. $\boldsymbol{A}$, The experimental scheme. $\boldsymbol{B}, \boldsymbol{C}$, No difference in the latency $(\boldsymbol{B})$ and distance swum $(\boldsymbol{C})$ to reach the hidden platform between the $t g-\mathrm{GCV}$ and wt-GCV mice during acquisition (latency: ANOVA, $F_{(1,20)}=0.138, p>0.71$; distance: ANOVA, $F_{(1,20)}=0.238, p>0.63 ;$ for $\operatorname{tg}-\mathrm{GCV}, n=$ 12 , for wt-G(V, $n=10)$. $D$, No difference in the duration in the target quadrants across the four probe trials between $t g-\mathrm{GCV}$ and wt-GCV mice (ANOVA, $\left.F_{(1,20)}=0.0035, p>0.95\right)$. Error bars represent \pm SEM.

GCV administration paradigm. Moreover, similar to our study, both studies reported the recovery of neurogenesis after drug withdrawal, despite that this recovery was slow and incomplete, possibly due to that a more quiescent, nestin-positive neural progenitor population was affected by prolonged infusion of GCV. A reduction of adult neurogenesis has also been reported in GFAP-tk transgenic mice (Garcia et al., 2004; Saxe et al., 2006).

In our experiments, we did not explore the functional significance of the newborn DGCs $<1$ week of age because newborn DGCs at this age, lacking any synaptic connection, most likely do not make significant contributions to learning and memory. On the other hand, the behavioral results described here did not reveal any subsequent effect from the reduction of a more mature, adult-born DGC population at 4-8 weeks of age (Fig. 4). However, physiological studies have revealed that adult-born DGCs, 4-6 weeks of age, also had enhanced plasticity and were preferentially incorporated into memory traces (Ge et al., 2007; Kee et al., 2007). We speculate that, while neurogenesis continues to affect learning and memory as DGCs mature, it may not be effectively revealed by the behavioral tasks described here, in part because these tasks were developed to assess behavioral changes following complete hippocampal lesions. New behavioral tasks need to be developed to address the specific modulatory roles of the DGCs at different developmental stages in learning and memory in the future.

Previous studies have provided substantial evidence for the correlation between adult hippocampal neurogenesis and cognitive ability (for review, see Zhao et al., 2008). For example, both voluntary exercise and exposure to enriched environment increase neurogenesis and enhance performance in spatial learning (Kempermann et al., 1997; van Praag et al., 1999). However, whether there is a causal relationship between neurogenesis and cognition is currently under debate (Meshi et al., 2006), and results from studies of the causal relationship between hippocampal neurogenesis and cognition are inconsistent and sometimes contradictory (for review, see Zhao et al., 2008). Because the lack of adult-born DGCs does not eliminate the function of hundreds of thousands of existing developmentally born DGCs, we speculate that adult-born DGCs should play a modulatory role to influence the function of the DG and their function can only be revealed using sensitive behavioral tests. For instance, we detected long-term retention deficit in mice with reduced imma- ture DGC population in the MWM task but not in contextual fear conditioning. The likely reason for this difference is that different degrees of hippocampal dependency are needed for MWM and contextual fear conditioning tasks (Dupret et al., 2008). Furthermore, mice may use different parallel compensatory networks in addition to the hippocampus to solve different behavioral tasks.

For similar reasons, it is not surprising that the results described here are consistent with some of the previous reports but disagree with others. For instance, similar to our findings, deficits in long-term spatial memory have been detected in rodents whose neurogenesis is greatly and permanently reduced by either irradiation or genetic manipulation (Snyder et al., 2005; Imayoshi et al., 2008; Jessberger et al., 2009). We can now include the conclusion that it is the immature adult-born DGCs that are important for long-term memory retention. The precise mechanism through which adult-born DGCs modulate long-term memory retention remains to be elucidated. Since the immature adultborn DGCs have low threshold for LTP induction and LTP is reduced in the absence of adult-born DGCs in irradiated mice (Saxe et al., 2006), we speculate that the LTP in newly born DGCs could contribute to the strength of memory. In addition to retention defects in MWM, acquisition deficits were observed in mice with reduced neurogenesis in two recent studies (Dupret et al., 2008; Zhang et al., 2008). We did not detect acquisition defects in MWM in our transgenic model, possibly due to differences in (1) approaches to manipulate neurogenesis, (2) the extent of neurogenesis reduction, (3) the population of adult-born DGCs affected, (4) the strain and species of animals used, and (5) detailed behavioral procedures. Nevertheless, we did detect deficits in Nestin-tk mice in the extinction of both spatial preference and contextual fear, which could represent the acquisition of new inhibitory learning. Therefore, in general, our study is in agreement with other genetic studies in the requirement of hippocampal neurogenesis for the formation of memory. In another study, Saxe and colleagues (Saxe et al., 2006) reported that neither acquisition nor memory defects were detected in irradiated mice, though this is likely due to the chronic elimination of hippocampal neurogenesis and the extensive pretraining procedure (Zhang et al., 2008).

In contextual fear conditioning paradigms, we have observed no deficit in the transgenic mice in which the number of immature DGCs was reduced (Fig. $7 B$ ). This finding is consistent with several previous reports, including our own (Shors et al., 2002; Dupret et al., 2008; Zhang et al., 2008), but disagrees with other studies (Saxe et al., 2006; Winocur et al., 2006). Whether the hippocampus is involved in anterograde amnesia for contextevoked fear is currently under debate. A recent report suggests that lesions of the hippocampus before training only affect the acquisition of contextual fear conditioning under specific experimental conditions [such as one-trial training (Wiltgen et al., 2006)]. Thus, revealing a role of neurogenesis in contextual fear conditioning is sensitive to specific training and testing conditions as well as parameters used to evaluate the memory. The long-term ablation of neurogenesis may also be necessary to the detection of impaired contextual fear conditioning. 
Despite only detecting the expression of the Nestin-TK transgene in the brain by RT-PCR (supplemental Fig. $1 A$, available at www.jneurosci.org as supplemental material), we cannot formally rule out the possibility that reduction of nestinexpressing proliferating progenitors in other tissues or in another brain area, especially the reduction of SVZ neurogenesis (supplemental Fig. 2, available at www.jneurosci.org as supplemental material), could lead to defects in learning and memory in tg-GCV mice (Li et al., 2003; Suárez-Rodríguez and BelkindGerson, 2004). However, we believe that reduction in SVZ neurogenesis is unlikely to exert a direct impact in our behavioral tests for the following reasons. First, although complete loss of olfactory function results in deteriorated behavioral performance in both MWM and contextual fear conditioning in olfactory bulbectomized rats (van Rijzingen et al., 1995; Jaako-Movits and Zharkovsky, 2005), only the adult-born granule neurons and periglomerular neurons are affected by the reduction of SVZ neurogenesis, and the main framework of the odor processing circuits in the olfactory bulb should be preserved even in the absence of adultborn neurons. Second, despite findings that SVZ neurogenesis is correlated with olfactory function (Gheusi et al., 2000; Enwere et al., 2004; Bath et al., 2008), drastic reduction of adult-born olfactory neurons by genetic ablation failed to establish a causal relationship between SVZ neurogenesis and odor discrimination or odor-associated memory (Imayoshi et al., 2008).

In conclusion, we have demonstrated here that adult-born DGCs during an immature stage of development make significant contributions to learning and memory. The specific role that the immature neurons play in DG function depends on progress made in identifying a function for the DG over all. During memory formation, the DG has recently been proposed to perform a pattern separation role by sparsifying and orthogonizing inputs into the hippocampus in both rodent models and human subjects (Gilbert et al., 2001; Rolls and Kesner, 2006; Leutgeb et al., 2007; McHugh et al., 2007; Bakker et al., 2008). The low threshold for LTP induction in immature DGCs may allow them to respond indiscriminately to different stimuli, which could affect pattern separation (Schmidt-Hieber et al., 2004; Aimone et al., 2006). A computational study in our lab suggests that immature DGCs may serve as pattern integrators to

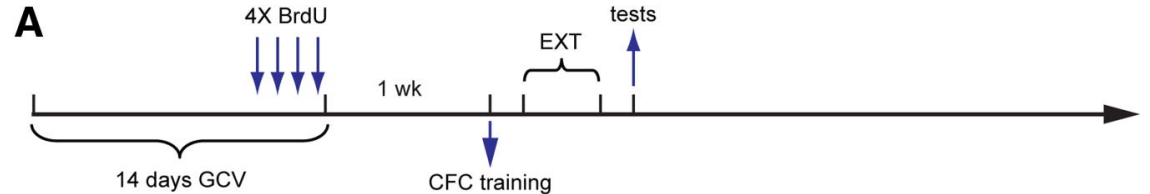

B

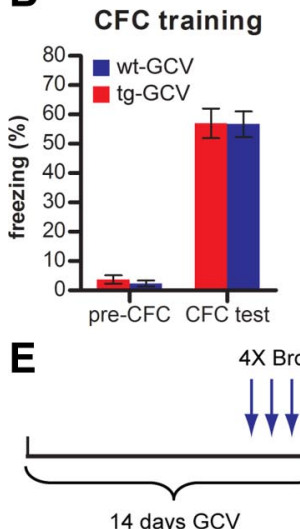

C

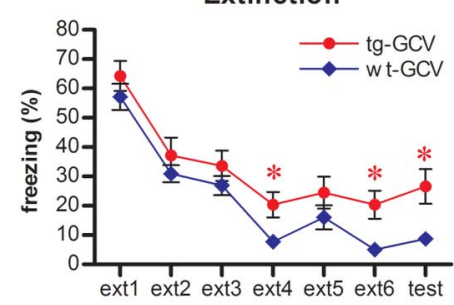

D Post-extinction tests
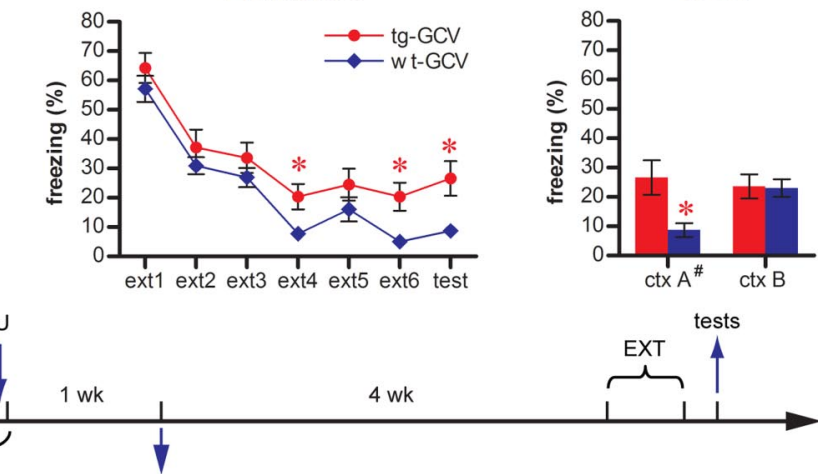

$\mathbf{F}$

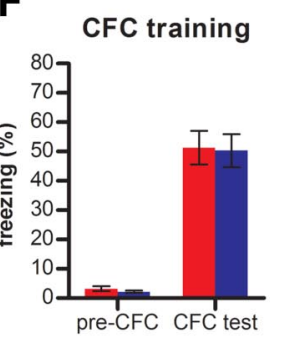

G

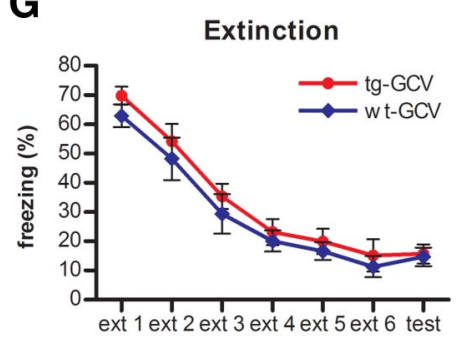

H Post-extinction
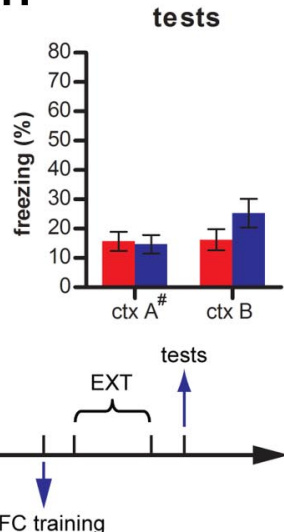

J

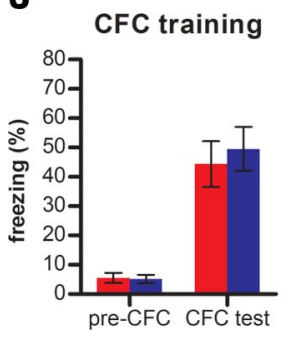

K

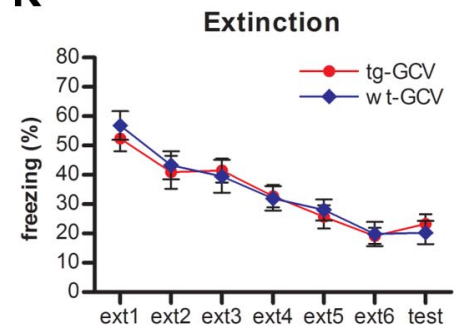

L Post-extinction
Figure 7. Impaired contextual fear extinction in GCV-treated Nestin-tk transgenic mice. $A$, Experimental scheme for $\boldsymbol{B}-\boldsymbol{D}$. $\boldsymbol{B}$, Contextual fear conditioning (CFC) is similar in tg-GCV and wt-GCV mice, as indicated by pre-CFC $\left(t_{(25)}=0.751\right.$, $p>0.46$; for tg-GCV, $n=14$, for wt-GCV, $n=13)$ and CFC ( $\left.t_{(25)}=0.0485, p>0.96\right)$ freezings. $C$, tg-GCV mice were impaired in the extinction of conditioned contextual fear response as compared to wt-GCV mice when extinction training occurred $24 \mathrm{~h}$ after conditioning (ANOVA, $F_{(1,25)}=4.429, p<0.046$ ). $D$, $\mathrm{tg}$ - GCV mice demonstrated significantly higher levels of freezing in training context A (ctx A) than wt-GCV mice $\left(t_{(25)}=2.74, p<0.011\right)$. In a considerably different context B (ctx B), tg-GCV and wt-GCV mice showed similar levels of freezing $\left(t_{(25)}=0.109, p>0.91\right)$. $E$, Experimental scheme for $\boldsymbol{F}-\boldsymbol{H}$. $\boldsymbol{F}$, CFC is similar in tg-GCV and wt-GCV mice, as indicated by pre-CFC $\left(t_{(18)}=1.09, p>0.28 ; n=10\right.$ for each group) and $C F C\left(t_{(18)}=0.120, p>0.90\right)$ freezings. $G, \mathrm{tg}-\mathrm{GCV}$ mice displayed extinction behavior similar to that of wt-GCV mice when extinction training occurred 4 weeks after conditioning (ANOVA, $\left.F_{(1,18)}=0.9315, p>0.34\right)$. $\boldsymbol{H}$, tg-GCV mice demonstrated similar levels of freezing in both $c t x A\left(t_{(18)}=0.229, p>0.82\right)$ and $\operatorname{ctx} B\left(t_{(18)}=1.50, p>0.15\right)$. $I$, Experimental scheme for $J-L$. J, CFC is similar in tg-GCV and wt-GCV mice, as indicated by pre-CFC $\left(t_{(18)}=0.163, p>0.87\right.$; for $\operatorname{tg}-\mathrm{GCV}, n=9$, for wt-GCV, $n=11)$ and $\mathrm{CFC}\left(t_{(18)}=0.467, p>0.64\right)$ freezings. $K$, $\operatorname{tg}$-GCV mice displayed extinction behavior similar to that of wt-GCV mice (ANOVA, $\left.F_{(1,18)}=7.359 \times 10^{-5}, p>0.99\right) . L, \mathrm{tg}-\mathrm{GCV}$ mice demonstrated similar levels of freezing in both ctx $A\left(t_{(18)}=1.42, p>0.17\right)$ and ctx $B\left(t_{(18)}=0.0761, p>0.94\right)$. "Data for ctx $A$ in $\boldsymbol{D}, \boldsymbol{H}$, and $\boldsymbol{L}$ are the same data for the last time point (test) in $\boldsymbol{C}, \boldsymbol{G}$, and $\boldsymbol{K}$, respectively. ext, Extinction trial. ${ }^{*} p<0.05$. Error bars represent \pm SEM. 
build artificial links among different events experienced during episodic memory formation (Aimone et al., 2009). Using chronic ablations of neurogenesis, a recent study suggested that an involvement of hippocampal neurogenesis in pattern separation (Clelland et al., 2009). It is our future challenge to investigate whether and at what stage of development the adult-born DGCs play a role in pattern separation.

\section{References}

Aimone JB, Wiles J, Gage FH (2006) Potential role for adult neurogenesis in the encoding of time in new memories. Nat Neurosci 9:723-727.

Aimone JB, Wiles J, Gage FH (2009) Computational influence of adult neurogenesis on memory encoding. Neuron 61:187-202.

Bakker A, Kirwan CB, Miller M, Stark CE (2008) Pattern separation in the human hippocampal CA3 and dentate gyrus. Science 319:1640-1642.

Bath KG, Mandairon N, Jing D, Rajagopal R, Kapoor R, Chen ZY, Khan T, Proenca CC, Kraemer R, Cleland TA, Hempstead BL, Chao MV, Lee FS (2008) Variant brain-derived neurotrophic factor (Val66Met) alters adult olfactory bulb neurogenesis and spontaneous olfactory discrimination. J Neurosci 28:2383-2393.

Clelland CD, Choi M, Romberg C, Clemenson GD Jr, Fragniere A, Tyers P, Jessberger S, Saksida LM, Barker RA, Gage FH, Bussey TJ (2009) A functional role for adult hippocampal neurogenesis in spatial pattern separation. Science 325:210-213.

Couillard-Despres S, Winner B, Schaubeck S, Aigner R, Vroemen M, Weidner N, Bogdahn U, Winkler J, Kuhn HG, Aigner L (2005) Doublecortin expression levels in adult brain reflect neurogenesis. Eur J Neurosci 21:1-14.

Drapeau E, Mayo W, Aurousseau C, Le Moal M, Piazza PV, Abrous DN (2003) Spatial memory performances of aged rats in the water maze predict levels of hippocampal neurogenesis. Proc Natl Acad Sci U S A 100:14385-14390

Dupret D, Revest JM, Koehl M, Ichas F, De Giorgi F, Costet P, Abrous DN, Piazza PV (2008) Spatial relational memory requires hippocampal adult neurogenesis. PLoS One 3:e1959.

Enwere E, Shingo T, Gregg C, Fujikawa H, Ohta S, Weiss S (2004) Aging results in reduced epidermal growth factor receptor signaling, diminished olfactory neurogenesis, and deficits in fine olfactory discrimination. J Neurosci 24:8354-8365.

Espósito MS, Piatti VC, Laplagne DA, Morgenstern NA, Ferrari CC, Pitossi FJ, Schinder AF (2005) Neuronal differentiation in the adult hippocampus recapitulates embryonic development. J Neurosci 25:10074-10086.

Faulkner RL, Jang MH, Liu XB, Duan X, Sailor KA, Kim JY, Ge S, Jones EG, Ming GL, Song H, Cheng HJ (2008) Development of hippocampal mossy fiber synaptic outputs by new neurons in the adult brain. Proc Natl Acad Sci U S A 105:14157-14162.

Fischer A, Radulovic M, Schrick C, Sananbenesi F, Godovac-Zimmermann J, Radulovic J (2007) Hippocampal Mek/Erk signaling mediates extinction of contextual freezing behavior. Neurobiol Learn Mem 87:149-158.

Gage FH (2000) Mammalian neural stem cells. Science 287:1433-1438.

Garcia AD, Doan NB, Imura T, Bush TG, Sofroniew MV (2004) GFAPexpressing progenitors are the principal source of constitutive neurogenesis in adult mouse forebrain. Nat Neurosci 7:1233-1241.

Ge S, Goh EL, Sailor KA, Kitabatake Y, Ming GL, Song H (2006) GABA regulates synaptic integration of newly generated neurons in the adult brain. Nature 439:589-593.

Ge S, Yang CH, Hsu KS, Ming GL, Song H (2007) A critical period for enhanced synaptic plasticity in newly generated neurons of the adult brain. Neuron 54:559-566.

Gheusi G, Cremer H, McLean H, Chazal G, Vincent JD, Lledo PM (2000) Importance of newly generated neurons in the adult olfactory bulb for odor discrimination. Proc Natl Acad Sci U S A 97:1823-1828.

Gilbert PE, Kesner RP, Lee I (2001) Dissociating hippocampal subregions: double dissociation between dentate gyrus and CA1. Hippocampus 11:626-636.

Hastings NB, Gould E (1999) Rapid extension of axons into the CA3 region by adult-generated granule cells. J Comp Neurol 413:146-154.

Hogan B, Beddington R, Constantini F, Lacy E (1994) Manipulating the mouse embryo: a laboratory manual. New York: Cold Spring Harbor Laboratory.

Imayoshi I, Sakamoto M, Ohtsuka T, Takao K, Miyakawa T, Yamaguchi M,
Mori K, Ikeda T, Itohara S, Kageyama R (2008) Roles of continuous neurogenesis in the structural and functional integrity of the adult forebrain. Nat Neurosci 11:1153-1161.

Jaako-Movits K, Zharkovsky A (2005) Impaired fear memory and decreased hippocampal neurogenesis following olfactory bulbectomy in rats. Eur J Neurosci 22:2871-2878.

Jessberger S, Clark RE, Broadbent NJ, Clemenson GD Jr, Consiglio A, Lie DC, Squire LR, Gage FH (2009) Dentate gyrus-specific knockdown of adult neurogenesis impairs spatial and object recognition memory in adult rats. Learn Mem 16:147-154.

Ji J, Maren S (2007) Hippocampal involvement in contextual modulation of fear extinction. Hippocampus 17:749-758.

Kee N, Teixeira CM, Wang AH, Frankland PW (2007) Preferential incorporation of adult-generated granule cells into spatial memory networks in the dentate gyrus. Nat Neurosci 10:355-362.

Kempermann G, Kuhn HG, Gage FH (1997) More hippocampal neurons in adult mice living in an enriched environment. Nature 386:493-495.

Lattal KM, Abel T (2001) Different requirements for protein synthesis in acquisition and extinction of spatial preferences and context-evoked fear. J Neurosci 21:5773-5780.

Leutgeb JK, Leutgeb S, Moser MB, Moser EI (2007) Pattern separation in the dentate gyrus and CA3 of the hippocampus. Science 315:961-966.

Li L, Mignone J, Yang M, Matic M, Penman S, Enikolopov G, Hoffman RM (2003) Nestin expression in hair follicle sheath progenitor cells. Proc Natl Acad Sci U S A 100:9958-9961.

Liu M, Pleasure SJ, Collins AE, Noebels JL, Naya FJ, Tsai MJ, Lowenstein DH (2000) Loss of BETA2/NeuroD leads to malformation of the dentate gyrus and epilepsy. Proc Natl Acad Sci U S A 97:865-870.

Maei HR, Zaslavsky K, Teixeira CM, Frankland PW (2009) What is the most sensitive measure of water maze probe test performance? Front Integr Neurosci 3:4.

McHugh TJ, Jones MW, Quinn JJ, Balthasar N, Coppari R, Elmquist JK, Lowell BB, Fanselow MS, Wilson MA, Tonegawa S (2007) Dentate gyrus NMDA receptors mediate rapid pattern separation in the hippocampal network. Science.

Meshi D, Drew MR, Saxe M, Ansorge MS, David D, Santarelli L, Malapani C, Moore H, Hen R (2006) Hippocampal neurogenesis is not required for behavioral effects of environmental enrichment. Nat Neurosci 9:729-731.

Mignone JL, Kukekov V, Chiang AS, Steindler D, Enikolopov G (2004) Neural stem and progenitor cells in nestin-GFP transgenic mice. J Comp Neurol 469:311-324.

Rolls ET, Kesner RP (2006) A computational theory of hippocampal function, and empirical tests of the theory. Prog Neurobiol 79:1-48.

Santarelli L, Saxe M, Gross C, Surget A, Battaglia F, Dulawa S, Weisstaub N, Lee J, Duman R, Arancio O, Belzung C, Hen R (2003) Requirement of hippocampal neurogenesis for the behavioral effects of antidepressants. Science 301:805-809.

Saxe MD, Battaglia F, Wang JW, Malleret G, David DJ, Monckton JE, Garcia AD, Sofroniew MV, Kandel ER, Santarelli L, Hen R, Drew MR (2006) Ablation of hippocampal neurogenesis impairs contextual fear conditioning and synaptic plasticity in the dentate gyrus. Proc Natl Acad Sci U S A 103:17501-17506.

Schmidt-Hieber C, Jonas P, Bischofberger J (2004) Enhanced synaptic plasticity in newly generated granule cells of the adult hippocampus. Nature 429:184-187.

Shors TJ, Miesegaes G, Beylin A, Zhao M, Rydel T, Gould E (2001) Neurogenesis in the adult is involved in the formation of trace memories. Nature 410:372-376.

Shors TJ, Townsend DA, Zhao M, Kozorovitskiy Y, Gould E (2002) Neurogenesis may relate to some but not all types of hippocampal-dependent learning. Hippocampus 12:578-584.

Singer BH, Jutkiewicz EM, Fuller CL, Lichtenwalner RJ, Zhang H, Velander AJ, Li X, Gnegy ME, Burant CF, Parent JM (2009) Conditional ablation and recovery of forebrain neurogenesis in the mouse. J Comp Neurol 514:567-582.

Snyder JS, Hong NS, McDonald RJ, Wojtowicz JM (2005) A role for adult neurogenesis in spatial long-term memory. Neuroscience 130:843-852.

Suárez-Rodríguez R, Belkind-Gerson J (2004) Cultured nestin-positive cells from postnatal mouse small bowel differentiate ex vivo into neurons, glia, and smooth muscle. Stem Cells 22:1373-1385.

Tashiro A, Sandler VM, Toni N, Zhao C, Gage FH (2006) NMDA-receptor- 
mediated, cell-specific integration of new neurons in adult dentate gyrus. Nature 442:929-933.

Tashiro A, Makino H, Gage FH (2007) Experience-specific functional modification of the dentate gyrus through adult neurogenesis: a critical period during an immature stage. J Neurosci 27:3252-3259.

Toni N, Teng EM, Bushong EA, Aimone JB, Zhao C, Consiglio A, van Praag H, Martone ME, Ellisman MH, Gage FH (2007) Synapse formation on neurons born in the adult hippocampus. Nat Neurosci 10:727-734.

Toni N, Laplagne DA, Zhao C, Lombardi G, Ribak CE, Gage FH, Schinder AF (2008) Neurons born in the adult dentate gyrus form functional synapses with target cells. Nat Neurosci 11:901-907.

van Praag H, Christie BR, Sejnowski TJ, Gage FH (1999) Running enhances neurogenesis, learning, and long-term potentiation in mice. Proc Natl Acad Sci U S A 96:13427-13431.

van Rijzingen IM, Gispen WH, Spruijt BM (1995) Olfactory bulbectomy temporarily impairs Morris maze performance: an ACTH(4-9) analog accellerates return of function. Physiol Behav 58:147-152.

Wiltgen BJ, Sanders MJ, Anagnostaras SG, Sage JR, Fanselow MS (2006)
Context fear learning in the absence of the hippocampus. J Neurosci 26:5484-5491.

Winocur G, Wojtowicz JM, Sekeres M, Snyder JS, Wang S (2006) Inhibition of neurogenesis interferes with hippocampus-dependent memory function. Hippocampus 16:296-304.

Yamaguchi M, Saito H, Suzuki M, Mori K (2000) Visualization of neurogenesis in the central nervous system using nestin promoter-GFP transgenic mice. Neuroreport 11:1991-1996.

Yu TS, Zhang G, Liebl DJ, Kernie SG (2008) Traumatic brain injuryinduced hippocampal neurogenesis requires activation of early nestinexpressing progenitors. J Neurosci 28:12901-12912.

Zhang CL, Zou Y, He W, Gage FH, Evans RM (2008) A role for adult TLX-positive neural stem cells in learning and behaviour. Nature 451:1004-1007.

Zhao C, Teng EM, Summers RG Jr, Ming GL, Gage FH (2006) Distinct morphological stages of dentate granule neuron maturation in the adult mouse hippocampus. J Neurosci 26:3-11.

Zhao C, Deng W, Gage FH (2008) Mechanisms and functional implications of adult neurogenesis. Cell 132:645-660. 